\title{
Migrant Youths and YouTube Entertainment: Media Participation in Post-Migrant Finland
}

\author{
By Mikko Malmberg, Mervi Pantti
}

\begin{abstract}
Recent media studies in Europe have stressed the importance of studying societies' negotiations on migration and the ability of migrants and other ethnic minorities to participate in these processes. Social media platforms have been widely praised for their openness to culturally diverse voices and representations. For minorities who have often been ignored and misrepresented in traditional media, these platforms arguably provide an empowering space where they can self-represent their identities, provide counter-representations to large and diverse audiences, and enhance their careers as media professionals. The video streaming social media platform, YouTube, is at the forefront of media participation. However, YouTube also has been criticized for promoting a highly commercialized culture of self-commodification and entertainment that maintains the status quo instead of enabling progressive social change. This study presents the results of an examination of the YouTube scene in Finland, a country with the lowest percentage of foreign-born inhabitants in Northern and Western Europe, where few YouTubers with migrant backgrounds have become increasingly visible within the last few years. Drawing on interviews with YouTubers, the study presents new insights into ethnic minority participation on YouTube and challenges binary oppositions between commercialism, entertainment and social change.
\end{abstract}

Keywords: YouTube, post-migrant society, ethnic minorities, self-representation, media participation, entertainment

Malmberg, Mikko \& Mervi Pantti: "Migrant Youths and YouTube Entertainment: Media Participation in Post-Migrant Finland", Culture Unbound, Volume 12, Issue 2, 2020: 275-292. Published by Linköping University Electronic Press: http://www. cultureunbound.ep.liu.se 


\section{Introduction}

Since it was founded in 2005, YouTube has grown to be one of the most popular social media platforms in the world (GlobalWebIndex 2019) and, in the process, provided its users a transnational space for self-representation and community building (Burgess \& Green 2018). The literature on YouTube highlights the opportunity it offers to ordinary people, including various marginalized groups, for self-representation (Burgess \& Green 2009, Raghavan 2009, Raun 2016, Thumim 2012). The cultural and political significance of self-representation practices is seen as central to challenging dominant representations in traditional media and offering visibility for minorities (Thumim 2012). However, reflecting upon the increasing commercialization of YouTube, the literature also stresses that YouTube's main focus is entertainment. This focus fosters self-commodification rather than critical discourse and political activism (Hess 2009, Marwick 2013). There is, however, a limited amount of work regarding ethnic minorities as media creators on YouTube. The literature, predominantly drawing on content analysis of user-generated videos or user comments, has focused on the construction of ethnic stereotypes and reproduction of racist discourses (Guo \& Harlow 2014, Guo \& Lee 2013, Kim \& Johnson 2018). The key question in previous literature has been whether YouTube functions as an alternative media that promotes recognition of minority communities and their participation in public discourse or contributes to maintaining the power relations (Guo \& Harlow 2014, Guo \& Lee 2013, Mallapragada 2017, Patterson 2017).

Moving beyond the opposition between alternative and mainstream media practices, as well as between politically motivated participation and participation in media entertainment production, our aim is to study how young Finnish YouTubers with migrant backgrounds make sense of their media production and how their practices are shaped by the omnipresence of migration discourse in societal and political life. Our approach is inspired by the idea of post-migrant media cultures (e.g., Kruse et al. 2019, Römhild 2017), a perspective that surpasses the traditional examination of how migrants use or become represented by media, and instead focuses on how media participation is changing as a consequence of migration. We aim to critically challenge the reproduction of oppositions, such as migrants and natives, imagining new solidarities and possibilities of conviviality in mediated everyday life. Such a perspective takes, as its starting point and object of study, the expansion of societal negotiation over migration (Römhild 2017: 72) in the context of contemporary interactive digital media cultures. Finally, the post-migrant perspective has been motivated particularly by the criticism levied against migration related research for further re-enforcing the essentialized differences between migrants and the so-called native population that it aims to deconstruct (e.g., Kruse et al. 2019, Römhild 2017). 


\section{Ethnic Minorities and Media Production in Post-migrant Societies}

Compared to other Western and Northern European countries, Finland currently has the lowest percentage (6.3\%) of foreign-born inhabitants (Eurostat 2018). Since the 2000s, immigration to Finland has considerably increased and, during the past decade alone, the number of people with migrant backgrounds has doubled (Statistics Finland 2019). However, not unlike in other European countries, the sociopolitical climate in Finland is characterized by the emergence of anti-immigration and racist attitudes (Hervik 2019, Sallamaa 2018) which has consequences for "visible minorities," particularly those of African descent (FRA 2018, Keskinen 2012, Rastas 2005). Arguably, the significance of the media in shaping inter-ethnic relations is growing as the channels and tools available for disseminating information, and the actors involved in media production, have become more diverse.

Traditionally, mainstream media is criticized for creating hierarchies between the majority "us" and the minority "others," as well as between different ethnic minority groups. Some of these groups can more easily be accepted into the hegemonic group while others remain positioned outside, usually based on physical appearance and/or cultural customs (e.g., Hall 1997, Hervik 2019, Siapera 2010). The representations of people with migrant backgrounds in Finnish traditional media have been largely contributing to similar exclusion and othering as reported in other countries. Literature focusing on news coverage concludes that migrant voices are largely ignored in public debates and their representations tend to be stereotypical and demarcated by their backgrounds as migrants (Haavisto 2011, Maasilta 2010, Niemi \& Perälä 2018, Pietikäinen 2002, Rekola 1996).

The possibilities for participation of migrants and other ethnic minorities in media production is a relatively neglected area compared to research on media representations and the use of media by migrants and minority groups. Historically, there have been few possibilities for ethnic minorities to take part in the mainstream media production in Finland (Kauranen \& Tuori 2002). One of the few exceptions has been Finland's public service broadcaster (Yle), which since the 1990s is obliged to represent the cultural diversity of the country. This has resulted in programming aimed at different ethnic communities, employment initiatives for ethnic minority media professionals, and most notably, so-called multicultural programming initiatives aimed at introducing majority and minority cultures to both migrant and majority audiences. In this regard, Yle's policy has been to move away from specialized programming, which has been criticized for "'ghettoizing' and accentuating differences rather than inspiring dialogue" (Horsti 2014: 47), and towards mainstreaming cultural diversity. This could be seen as an official attempt by Finland to move towards post-migrant media culture and conviviality: togetherness-in-difference. 
Community media outlets by migrants and other ethnic minoritiessometimes called alternative media or ethnic minority media-have historically been recognized as platforms for resistance against marginalization by traditional media, as minorities can represent themselves and provide counter-representations in the public sphere (e.g., Bailey et al. 2007, Atton 2015). Like public service media, community media outlets are seen as particularly effective in providing alternative, empowering representations because they largely operate with non-commercial motives. In Finland, community media outlets, such as magazines and radio stations, have been relatively numerous despite the small sizes of many minority communities (e.g., Davydova-Minguet 2017, Kauranen \& Tuori 2002). Such outlets of media play an important role for minorities in building and preserving different ethnic identities (Kauranen \& Tuori 2002, Mitra 2006). However, by specifically targeting specialized audiences, a "separate public sphere" is formed and, thus, the potential to increase recognition of minority concerns within the mainstream public sphere, or promote inter-ethnic understanding, is limited (Budarick \& Han 2015, Husband 1998).

As it is often stated, social media platforms have allowed "former audiences," including underrepresented minorities, to become media producers themselves (e.g., Castells 2007, Cunningham \& Craig 2019, Siapera 2010). Popular social media platforms have been acknowledged as viable spaces for minorities to represent themselves, build individual and group identities, and provide counter-representations that challenge their misrepresentations and invisibility in the mainstream public sphere (e.g., Florini 2014, Grasmuck et al. 2009, Mainsah 2011). What makes YouTube particularly appealing to minority groups is the potential to reach larger audiences beyond small specialized audiences based on ethnicity or language, and a relatively low barrier for participation. However, being what YouTube calls a "creator"-an active user who produces videosgenerally requires more skills and time than being an active user on most other social media platforms. Being the second most visited website in the world, these large audiences enable-arguably better than any other social media platform at the moment-individuals to participate in what Castells (2007) calls "mass self-communication."

\section{YouTube and Social Change}

YouTube has consistently advertised itself as a key space for grassroots creativity, and in its initial phase, research on YouTube focused on its capacity to facilitate and archive vernacular production (e.g., Burgess \& Green 2009, Jenkins 2006, Lange 2007). Over the past years, scholars have noted the expansive commercialization of YouTube trickling down from commercial brands distributing popular 
entertainment to individual content creators who have turned the logics of social networking into economic or political profit (Cunningham et al. 2016, Hou 2018, Kim 2012, Raun 2018). YouTube, then, cannot be analyzed solely in terms of amateurism or as an alternative to mainstream media (van Dijck 2013) but should be understood as a hybrid commercial environment.

As Arthurs et al. (2018) note, amateur aesthetics have become a powerful device for "entrepreneurialization of the self." Dreaming of popularity, YouTubers employ various self-representation techniques to build their popularity on the platform, in the hope of gaining fame or a "microcelebrity" status among a niche online audience (Kavoori 2015, Marwick 2013, Senft 2013). Authenticity - the appearance of being "real" - is often noted as a key technique for gaining attention on the platform (e.g., Burgess \& Green 2018, Cunningham \& Craig 2019, Strangelove 2010). This is reflected in the popular genres on YouTube, where high-production value and carefully crafted narratives of the traditional broadcast media are replaced with low-budget genres built around open and expressive individuals, for example: vlogs in which YouTubers monologue in front of the camera or show their everyday life; tutorials in which YouTubers teach various skills to their audiences; reaction and review videos in which YouTubers judge or simply react to videos that are often made by other YouTubers; or public prank/ interview/experiment videos in which the YouTubers interact with the public by doing practical jokes on them, interviewing them or testing how they react to surprising situations (e.g., Burgess \& Green 2018, Cunningham \& Craig 2019, Strangelove 2010).

The notion of YouTube being a platform for progressive social change is also largely based on this idea of authenticity appeal; marginal groups are able to represent themselves and broadcast their messages without editorial intervention, while having the prospect of gaining public visibility previously available only to those with access to broadcast media (Arthurs et al. 2018). However, the critics argue that YouTube's structural focus on commerciality negatively affects its potential to act as a platform for progressive cultural change (Hess 2009, Marwick 2013). Marwick (2013), for example, makes the case that YouTube and other social media platforms foster communication that follows the logics of modern neoliberal capitalism and thus ultimately only benefit the status quo.

The literature on YouTubers of ethnic minorities focuses on their engagement with progressive cultural politics and resistance to dominant representations. In this respect, these studies present contradicting findings and arguments, partly derived from different understandings of the power relationship between structure and agency on the platform. On the one hand, studies that focus on ethnic minority activists-or more broadly, on counter-representations of marginalized identities-tend to focus primarily on the YouTubers' agencies and 
give very little consideration to YouTube's structural logics (e.g., Mallapragada 2017, Patterson 2017, Vergani \& Zuev 2011). On the other hand, studies focusing on ethnic minority YouTubers-primarily in the North American scene-who create more commercially aimed videos, argue that YouTube's internal logic that fosters entertainment and self-commodification (Guo \& Lee 2013, Lopez 2016) results in content in which "racism becomes sublimated and there is no intentional engagement with the politics of representation" (Lopez 2016: 156). Critics also argue that overall racial and ethnic representations on YouTube work to reinforce stereotypes and maintain the status quo (Guo \& Harlow 2014). However, more recent literature has underscored the complexity of the politics of representation taking place on the platform and stressed that commercially motivated content creation and activism with a progressive agenda are often inextricably intertwined in the practices of marginalized minorities on YouTube (Cunningham \& Craig 2019, Raun 2018).

\section{Method and Sample}

Overall, the existing literature about ethnic minorities on YouTube presents at least two shortcomings that the current paper can help to balance. First, most of these studies focus entirely or primarily on the video content on YouTube. Following Awad (2014), we argue that a more nuanced understanding about the relationship between the structure of YouTube and agency of the creators can be achieved by having direct conversations with the creators. Studying social media should include ethnographic approaches that examine how these communication technologies are integrated into people's everyday lives. Second, the existing studies predominantly focus on the North American YouTube scene. Therefore, there is not only a lack of diversity regarding different sociocultural contexts in the research, but also, because the North American scene dominates YouTube globally, there is arguably a lack of consideration for the importance of particular sociocultural context in YouTube practices.

Semi-structured interviews, conducted in Finnish by the first author, were used as the primary method in this study. The interviewees were found by browsing new and popular videos on the Finnish-language YouTube and by obtaining recommendations from the interviewees. In total, 12 YouTubers of African and Asian backgrounds were interviewed for this study. The small number of interviews is reflective of the small number of YouTubers with migrant backgrounds in Finland. In Finnish context, where only around $6 \%$ of the population is of foreign background, active YouTubers of migrant backgrounds are few. All interviewees are young males, reflecting the male dominance on YouTube (Döring \& Mohseni 2018, Wotanis \& McMillan 2014). While some female YouTubers were contacted, 
very few women of migrant backgrounds are active in the Finnish YouTube scene. This may be partly due to the negative and hostile culture of the platform that particularly increases the risk of women with minority backgrounds becoming targets of harassment due to their marginalized intersectional identities (cf. Lopez 2016).

Following the post-migrant perspective (Kruse et al. 2019, Römhild 2017), the interviews were aimed at examining the Finnish YouTube scene and the participation of migrant youths in it. Moreover, the focus was on the "the variety of approaches around participation" (Stehling et al. 2019: 5) to highlight the heterogeneity of identities and experiences that are also reflected in media production (e.g., Aksoy \& Robins 2000, Madianou 2005). The interviewees were not asked questions that directly relate to the research question (Kvale 1996), but rather they were asked general questions that allowed them to reflect on their YouTube practices, such as what motivates them to be YouTubers and how they come up with ideas for their videos. Additionally, the YouTubers' videos were used as a complementary data to have an understanding of the kinds of content they produce. Some questions were related to specific videos, such as videos in which the YouTubers explicitly or implicitly engage with the politics of representation regarding migrants or their respective ethnic communities. It is worth underscoring that the authors belong to the majority group. This adds an extra dimension to the power relations between the interviewer and the interviewee in a study that focuses on ethnic minorities. Particularly, the interview situation can contribute to the essentialization and marginalization of ethnic minorities, if the participants are framed as only being interesting and worthwhile interviewees because of their ethnicity. To avoid such framing, the interviewees were approached first and foremost as YouTubers, who are experts in their field of media creation.

In order to protect the interviewees who reported having experienced online harassment, this article does not contain any specific references to their identities or their YouTube content. Some of them arrived in Finland as young children and others were born in Finland to first-generation migrant parents. They are all in their late teens or early twenties and live in Finland's main population centers, most of them in the capital area. Most of the interviewees have individual channels, but some have group channels on which they co-produce content. Their videos are mostly aimed at Finnish-speaking audiences (some content is in English) and they are relatively popular within the Finnish YouTube scene. While none of them make it close to being amongst the 100 most popular Finnish YouTubers based on the number of subscribers, each of their channels have several thousand subscribers, which is a considerable accomplishment given that having over 2000 subscribers places a YouTube channel amongst the top 15\% of all Finnish YouTube channels (SuomiTube.fi 2020). 


\section{A venue for solidarity and self-entrepreneurship}

YouTubers of migrant backgrounds have a small but rather tight knit community in Finland. Most of the interviewed YouTubers knew each other and collaborated with each other in different ways. Some participants were friends before they became video creators, and in such cases, one typically encouraged and helped others to start producing videos. Others connected after they had already become video creators. Interviewee 1 described how the other YouTubers began contacting him after finding his channel:

These guys with foreign backgrounds started contacting me through Snapchat. I remember that they sent messages like, "Hey, I saw your videos. I also have a channel. It would be very nice to get to know you and to collaborate."

Collaboration with other YouTubers obviously has an instrumental value; as by promoting each other's channels, YouTubers are able to gain more visibility (Burgess \& Green 2018). However, participants did not address collaboration as a means of propelling their popularity on YouTube. Rather, collaboration was seen as an essential part of their everyday life and cultural identity. Indeed, the dominant theme in participants' narratives was the friendship formed around, and sustained by, their common interest in creating videos. These aspiring media producers stressed that the community that they created has an important role in supporting their YouTube related creative practices. Interviewee 2 detailed how mutual emotional support is used to inspire regular video production:

Now that we have built this little team, it's really important for me. Like, if [Interviewee 3] doesn't have the energy to make a video, I can tell him that, "I know that you want to do it" and, like, inspire others.

The collaboration and feelings of commonality with other ethnic minority YouTubers supports their sense of community on YouTube. YouTube then represents a space of inclusion that has allowed the participants to create new forms of solidarity through identifications with other "others" (Rastas 2013).

The sense of community is also formed on their conflicted sense of belonging and experiences of exclusion due to their ethnic minority backgrounds. According to Interviewee 3, "similar cultural backgrounds"-reflected in lifestyle choices such as not drinking alcohol unlike many of their ethnically Finnish peersmade them bond with each other. Interviewee 4 highlighted how sharing migrant backgrounds and experiences help them to see past stereotypes and become friends: 
We become friends very easily and-how could I say-like when we see that another foreigner dared to do the same thing in this Finnish society, we feel a connection with them. And overall, it's easier for a foreigner to get to know another foreigner rather than a Finn. I don't want to generalize, but a Finn usually has, like, a fixed image of a foreigner, something that a foreigner doesn't have of another foreigner so it's easier to become friends.

As the above comment illustrates, the interviewees generally do not identify themselves as "immigrants" because of the negative stereotypes the term invokes (Honkasalo 2003, Rastas 2013), but prefer to refer to themselves as "foreigners," as also noted by earlier studies on the ethnic minority youth in Finland (Keskisalo 2003). For the self-identification and forming of collective identity, the "daring" mentioned in the above comment similarly plays an important role. Several participants gave meaning to their YouTube practices in terms of rejecting or exceeding the subject positions, such as that of an immigrant, offered for them by the surrounding society.

YouTube, then, represented a sphere where they could negotiate their positioning through self-expression and gain social recognition. The potential for exceeding the social positioning was boldly expressed by Interviewee 1 who expressed a goal of "taking over" the Finnish YouTube scene with his fellow YouTubers of "foreign" backgrounds. Such aspiration shows that these YouTubers are not in the business of creating "alternative media" or "ethnic media," defined as media produced by and for ethnic minorities (Yu \& Matsaganis 2019). Their YouTube videos are not produced for particular ethnic communities or just for youth with migrant backgrounds, but for the (young) social media audience in Finland as a whole. In fact, their shared motivation to produce videos was to showcase their talent in order to have a career in the Finnish media, particularly in the entertainment industry. While being a professional YouTube creator is not a common occupation anywhere, Finnish YouTube's relatively small reach only allows a very few to make a living as an independent YouTuber. YouTube, thus, was seen as a springboard to careers in the larger entertainment industry. Some of them aspire to become actors or artists, while others want to work behind the scenes as writers, videographers or editors. These aspirations are also reflected in the kinds of content they create.

\section{Appropriate Content for Ethnic Minority YouTubers}

The YouTube practices of the interviewed YouTubers revealed much about the context in which their video production takes place. While YouTube provided a 
space of solidarity and agency, and even potential success, it also became a site of restrictive categorizations. The cultural production of these YouTubers was shaped and fractured by expectations and categories ascribed to them by both majority group and ethnic minority groups based on their ethnic background.

While the interviewees generally rejected being labelled as an immigrant or being categorized as a member of a particular ethnic community, they also recognized the value of their "otherness" for building a personal brand. Some of them exploited the opposition between them and white native Finnish people in their videos to generate attention. Thus, being labeled as an immigrant was also perceived as a branding tool. Interviewee 3 detailed that his migrant background made him stand out from other Finnish video producers as exotic and different. He admits that he sometimes tactically uses it for gaining visibility on the platform. Humorous interview videos, for example, are built around provoking questions such as "which nationality would you remove from Finland?" or "would you like to be white or black?"

At the same time, most of the participants emphasize that their migrant backgrounds have little or nothing to do with the kinds of videos they create. Accordingly, Interviewee 6 expressed his desire to be seen as a "normal" YouTuber:

For example, when we go out to interview people or something like that, like "social interaction," they [interviewees] are usually very surprised like, "Hey, you speak Finnish pretty well." With this [YouTube videos] I want to communicate that even though I'm an immigrant-I have dark hair, hairy arms-it doesn't mean that I'm very different as a human than, for example, a native Finn. Like, if you watch my videos, they could be compared to videos of any Finnish YouTuber to some extent. So, I'm just trying to show that I, an immigrant, am a normal person just like anybody else.

While their production was focused on entertainment, some of the YouTubers were interested in doing more critical content. However, as Interviewee 3 explained, being too political, especially with regard to issues related to immigrants, can be a risky move for a YouTuber with a migrant background. In his case, the reason is not YouTube's internal "logic that prefers entertainment to serious discussions of social issues" (Guo \& Lee 2013: 402), that is, fear of jeopardizing his popularity, but rather, his perception of his own position in the Finnish entertainment industry in which he wants to have a career:

These days you can be too political for some $[\ldots]$ because when you are different you can also be a risk somehow. It's like, harder to brand you 
[...] these kinds of big production companies they think about these things a lot. That's why I've also tried to pay attention to these things because it's good to be aware of what these people are looking for.

While aiming to address a wider audience, the interviewed YouTubers are also struggling with expectations to serve their "own community." Interviewee 6 highlighted how YouTubers of migrant backgrounds also feel pressure to be explicitly political about immigration or ethnic minority-related issues. Because of their relatively large audiences, some interviewees feel that they are expected to act as spokespersons for their ethnic communities, or people with migrant backgrounds in general, in the ongoing immigration debate in Finland. However, their focus on entertainment clashes with this idea.

Some YouTubers mainly create prank videos and "interviews" in which they interview people in public places such as shopping malls. These kinds of videos in which YouTubers solicit reactions from strangers by pranking them or asking provoking questions are very popular worldwide but also prone to criticism. Prank videos are controversial in general because of their potential abusiveness, but here the criticism often arises from the ethnic and migrant backgrounds of the YouTubers, and not simply the content. As explained by Interviewee 5, producing this kind of content can be perceived by the majority population as a transgression of what people with an immigrant background, i.e. non-white people, should do:

They say, like, "Why are these foreigners doing this stuff?" and, like, "Why are these unemployed people in Finland?" and, "Is this what they do with their free time?" and stuff like that. Even though we are students, we get a lot of this unemployed stuff.

They receive criticism also, as Interviewee 1 described, from their own ethnic community. Typically this is connected to the fear of damaging the public image of the wider group which they are assumed to represent. Interviewees then are acutely aware of their "burden of representation" - that their online actions are likely to be projected onto their ethnic group (see Shohat \& Stam 1994):

One of my biggest worries is that it only takes one person to do something for everyone to get blamed for. Like being on the social media as a person with Somali background, it's not just the people with Finnish backgrounds who berate us, it's also our own countrymen [...] I thought at first that they would be supportive, but they berate. 
In this particular case, the interviewee had turned this negative reception by other people of Somali descent into motivation to inspire other youths of migrant backgrounds to express themselves freely.

\section{Role Models of Self-expression}

Even though the interviewees did not define their video production in terms of their ethnic identity, their motivation for self-expression also reflected some of the key rationales of ethnic media, namely those of misrepresentation and underrepresentation of ethnic minorities in the traditional media. In their interviews, young YouTubers described the difficulty they felt about others' views of them. The mere participation in media production then functions as an alternative self-representation, as explained by Interviewee 1 :

What motivates me is that I want to break stereotypes, because when I started $[\ldots]$ a very close friend told me, "You're not going to be anything." I asked him, "Why I won't be anything, tell me?" and he just kept repeating, "Because we're in Finland, open your eyes already." Those words always echo in my head, but that's why I've always wanted to show them that everything is possible.

Indeed, YouTube is largely seen by the interviewees as a space where they can express themselves and be their real selves as opposed to performing a role in order to fit in. As Suurpää (2002) notes, people with migrant backgrounds are often expected to carefully position themselves in order to showcase their successful integration. Especially in the current context of pronounced antiimmigrant sentiment, immigrants must demonstrate their deservingness to the dominant public. As Interviewee 10 described, their authentic identity provides contrast against stereotypes created and enforced by the traditional media that "all Muslims are terrorists or that all black people are rapists."

Even if many of the interviewees claimed that they are not interested in political activism or taking part in debates around immigration and cultural diversity (cf. Lopez 2016), at the same time they stressed that their YouTube presence potentially empowers those in their audience who are also of migrant backgrounds. As Interviewee 3 explained, such feeling is often related to the feedback they receive: "Now I've gotten passionate because I've noticed that I motivate many youths of migrant backgrounds to express themselves." In this sense, these YouTubers also recognize themselves as "role models" for young people identifying themselves in multiple ways and not solely drawing on their ethnicity. Thus, lack of explicitly political or "serious" content does not necessarily 
mean that the YouTuber does not have any political intentions. As Interviewee 6 noted, entertainment can also be a strategic choice for critical aims: "You can talk about things that are going on in the world, but at the same time make it seem like entertainment. I think that's a winning combination." The playful humor, which is often the predominant mode in their videos, makes it possible to address the negative attributions related to people with migrant backgrounds, and thereby, question and ridicule them.

By becoming video creators, these YouTubers have made images of complex non-native identities more accessible to broader Finnish audiences. At the same time, this makes them vulnerable to violence and stereotypes that exist offline. Social media has also enforced voices that attempt to further marginalize minorities or consider migrants as a threat to Finnish culture. For example, social media has had a central role in empowering the anti-immigration movements in Finland (Sallamaa 2018). The interviewees stated that videos where their ethnic or migrant background is explicitly visible receive an especially high number of racist comments. For example, Interviewee 3 described the reception of his first video on the platform in which he discussed living between two cultures. What began as a positive experience of rapidly gaining thousands of views and hundreds of followers accompanied by predominantly positive feedback, soon turned negative as his video was shared on an anti-immigration online forum:

One night, I was sleeping and then I started receiving notifications to my phone, "ding, ding, ding," [...] Then I saw that it was like "kill yourself," "go back to your country," [...] Somebody had shared it on a forum and wrote, "he doesn't know Finnish and he is from there and there," $[\ldots]$ So that was my first experience of YouTube culture.

While the racist comments did not make Interviewee 3 remove the video or to stop expressing his ethnic identity in his future videos, he did eventually disable the comment section on that video because the negative and racist comments he kept receiving took away from his ability to focus on creating new content. The experiences of these YouTubers highlight the abusiveness that exists on the YouTube comment sections (e.g., Burgess \& Green 2018, Strangelove 2010) and how racism on YouTube is a significant factor that can affect minority YouTubers and their practices on the platform (e.g., Murthy \& Sharma 2019, Sugars 2015).

\section{Discussion and Conclusion}

The findings of this study bring new insights into the realities of migrant-background youths in post-migrant societies who participate in media creation 
on YouTube. In many ways, YouTube appears as an empowering space for the interviewees, where they can build supportive communities with other like-minded creators, build their careers as media professionals, and challenge the restricting and marginalizing subject positions offered to them by the surrounding society. On the other hand, despite YouTube seemingly being a platform that allows unrestricted self-representation free of the gatekeepers of the traditional media, these YouTubers still experience many of the same challenges that ethnic minorities have always faced regarding their media participation. For example, the "burden of representation" (Shohat \& Stam 1994) that forces these youth to always consider how their video content is reflected upon the larger community that they are seen to represent. Nevertheless, these findings show that YouTube as a platform has considerable potential to facilitate more convivial media cultures in Post-Migrant societies.

Regarding the criticism levied against YouTube for being a platform that fosters entertainment and self-commodification, reinforcing the status quo instead of enabling progressive social change (Guo \& Harlow 2014, Guo \& Lee 2013, Hess 2009, Lopez 2016, Marwick 2013), the ethnographic data of this study challenges such binary readings. As the findings highlight, regardless of what kinds of videos these YouTubers create, their creative process involves much more complex considerations than simply following the inner logics of YouTube. Overall, the findings underscore the need to pay more attention to the local sociocultural context and how the YouTube practices are intertwined with the realities of everyday life. In many ways, these findings are similar to studies that highlight the interconnectedness of commercially motivated content creation and activism with a progressive agenda in the YouTube practices of marginalized minorities (Cunningham \& Craig 2019, Raun 2018). The interviewees usually began their YouTube practices because of artistic motivations. After gaining some visibility on the platform, they also became commercially motivated, as they realized how the platform can help them to build a career in media. At this point, many of the interviewees also began to have motivations that could be described as political, because they became aware of the cultural influence that they now had and wanted to use that to aspire progressive change regarding issues that they have experienced in their everyday lives, some of these issues being for example stereotyping, marginalization and racism. Additionally, these motivations were also related to the interactions that they had with their diverse audiences.

To conclude, the findings of this study demonstrate how YouTube is a platform that has the potential to contribute to a progressive transformation of post-migrant media cultures. Considering YouTube's great global popularity and cultural significance, it is important to study how migrants and other ethnic minorities who have historically been ignored and misrepresented within the 
traditional media, are able to participate on the platform. Therefore, this topic deserves much more research in the future. The topic also deserves continued attention in Finland. As the country's cultural diversity keeps increasing and the next generations of migrant youth begin creating videos on YouTube in growing numbers, their YouTube practices will most likely happen in a vastly different context.

Mikko Malmberg is a doctoral student at the University of Helsinki's Faculty of Social Sciences. His $\mathrm{PhD}$ project examines how media personalities of migrant background in Finland contest dominant representations of migrants and Finnishness. Malmberg has a master's degree in Media Studies from Erasmus University Rotterdam. E-mail: mikko.malmberg@helsinki.fi

Mervi Pantti is Professor in Media and Communication Studies at the Faculty of Social Sciences, University of Helsinki. Her research is concerned with the emotional dimension of mediated communication, crisis and disaster reporting and humanitarian communication. She has published close to 100 articles in academic journals and edited books. Currently, she serves as associate editor of Journalism Studies.

\section{References}

Abidin, Crystal (2015): "Micro-Microcelebrity: Branding Babies on the Internet," M/C Journal, 18:5.

Arthurs, Jane, Sophia Drakopoulou \& Alessandro Gandini (2018): "Researching YouTube," Convergence, 24:1, 3-15.

Atton, Chris (2015): "Introduction: Problems and Positions in Alternative and Community Media," Chris Atton (ed.): The Routledge Companion to Alternative and Community Media, New York: Routledge, 1-18.

Awad, Isabel (2014): "Journalism, Poverty, and the Marketing of Misery: News From Chile's 'Largest Ghetto'," Journal of Communication, 64, 1066-1087.

Bailey, Olga, Bart Cammaerts \& Nico Carpentier (2007): Understanding Alternative Media, Maidenhead: Open University Press.

Budarick, John, \& Gil-Soo Han (2015): "Towards a Multi-Ethnic Public Sphere? African-Australian Media and Minority-Majority Relations," Media, Culture \& Society, 37:8, 1254-1265.

Burgess, Jean \& Joshua Green (2009): YouTube: Online Video and Participatory Culture, Cambridge: Polity Press.

Burgess, Jean \& Joshua Green (2018): YouTube: Online Video and Participatory Culture, 2nd ed., Cambridge: Polity Press.

Castells, Manuel (2007): "Communication, Power and Counter-Power in the Network Society," International Journal of Communication, 1, 238-266.

Cunningham, Stuart, David Craig \& John Silver (2016): "YouTube, Multichannel Networks and the Accelerated Evolution of the New Screen Ecology," Convergence, 22:4, 376-391.

Cunningham, Stuart \& David Craig (2019): Social Media Entertainment: The New Intersection of Hollywood and Silicon Valley, New York: New York University Press. 


\section{Culture Unbound}

Davydova-Minguet, Olga (2017): "Suomen venäjänkielinen media ja monietninen julkisuus," Idäntutkimus, 24:3, 3-19.

Döring, Nicola \& M. Rohangis Mohseni (2018): "Male Dominance and Sexism on YouTube: Results of Three Content Analyses," Feminist Media Studies, 1-13.

Eurostat (2018): "Foreign-Born Population by Country of Birth, 1 January 2017," available at:

http://ec.europa.eu/eurostat/statistics-explained/index.php?title=File:Foreign-born population by country of birth, 1 January 2017 .png (Accessed 24/01/20).

Florini, Sarah (2014): "Tweets, Tweeps, and Signifyin": Communication and Cultural Performance on 'Black Twitter'," Television \& New Media, 15:3, 223-237.

FRA (2018): Second European Union Minorities and Discrimination Survey: Being Black in the EU, available at: https://fra.europa.eu/sites/default/files/fra uploads/ fra-2018-being-black-in-the-eu en.pdf (Accessed 24/01/20).

GlobalWebIndex (2019): "Social: GlobalWebIndex's Flagship Report on the Latest Trends in Social Media," available at: https://www.globalwebindex.com/hubfs/ Downloads/Social-H2-2018-report.pdf (Accessed 24/01/20).

Grasmuck, Sherri, Jason Martin \& Shanyang Zhao (2009): "Ethno-Racial Identity Displays on Facebook," Journal of Computer-Mediated Communication, 15:1, $158-188$.

Guo, Lei \& Summer Harlow (2014): "User-Generated Racism: An Analysis of Stereotypes of African Americans, Latinos, and Asians in YouTube Videos," Howard Journal of Communications, 25:3, 281-302.

Guo, Lei \& Lorin Lee (2013): "The Critique of YouTube-Based Vernacular Discourse: A Case Study of YouTube's Asian Community," Critical Studies in Media Communication, 30:5, 391-406.

Haavisto, Camilla (2011): Conditionally One of "Us": A Study of Print Media, Minorities and Positioning Practices, doctoral dissertation, University of Helsinki.

Hall, Stuart (1997): “The Spectacle of the 'Other,"' Stuart Hall (ed): Representation: Cultural Representations and Signifying Practices, London: SAGE Publications, 223-290.

Hervik, Peter, ed. (2019): Approaches to Social Inequality and Difference: Racialization, Racism, and Anti-Racism in the Nordic Countries, Cham: Palgrave Macmillan.

Hess, Aaron (2009): "Resistance Up in Smoke: Analyzing the Limitations of Deliberation on YouTube," Critical Studies in Media Communication, 26:5, 411-434.

Horsti, Karina (2014): “"The Cultural Diversity Turn: Policies, Politics and Influences at the European Level," Karina Horsti, Gunilla Hultén \& Gavin Titley (eds): National Conversations: Public Service Media and Cultural Diversity in Europe, Bristol: Intellect, 43-60.

Hou, Mingyi (2019): "Social Media Celebrity and the Institutionalization of YouTube," Convergence, 25:3, 534-553.

Honkasalo, Veronika (2003): "Voiko jäsenyyttä valita?: Nuorten maahanmuuttajien tulkintoja suomalaisuudesta ja rasismista," Päivi Harinen (ed.): Kamppailuja jäsenyyksistä: Etnisyys, kulttuuri ja kansalaisuus nuorten arjessa, Helsinki: Finnish Youth Research Network, 158-186.

Husband, Charles (1998): "Globalisation, Media Infrastructures and Identities in a Diasporic Community," Javnost-The Public, 5:4, 19-33.

Jenkins, Henry (2006): Convergence Culture: Where Old and New Media Collide, New York: New York University Press.

Kauranen, Ralf \& Salla Tuori (2002): "Mapping Minorities and their Media: The National Context_Finland", available at: http://www.lse.ac.uk/media@1se/ research/EMTEL/minorities/reports.html (Accessed 23/02/19).

Kavoori, Anandam (2015): "Making Sense of YouTube," Global Media Journal, $24: 13,1-25$. 


\section{Culture Unbound}

Journal of Current Cultural Research

Keskinen, Suvi (2012): "Limits to Speech? The Racialised Politics of Gendered Violence in Denmark and Finland," Journal of Intercultural Studies, 33:3, 261-274.

Keskisalo, Anne-Mari (2003): "Suomalais- ja maahanmuuttajanuorten vuorovaikutusta joensuulaisen koulun arjessa," Päivi Harinen (ed.): Kamppailuja jäsenyyksistä: Etnisyys, kulttuuri ja kansalaisuus nuorten arjessa, Helsinki: Finnish Youth Research Network, 122-57.

Kim, Jin (2012): "The Institutionalization of YouTube: From User-Generated Content to Professionally Generated Content," Media, Culture \& Society, 34:1, 53-67.

Kim, Linda \& Brooke Johnson (2018): "Contesting Race in YouTube's K-Town: 'It's White People in Asian Disguises," The Journal of Social Media in Society, 7:1, 78-105.

Kruse, Merle-Marie, Miriam Stehling and Tanja Thomas (2019): "Introduction," Tanja Thomas, Merle-Marie Kruse, Miriam Stehling (eds.): Media and Participation in Post-Migrant Societies, London: Rowman \& Littlefield International, xv-xxvi.

Kvale, Steinar (1996): InterViews: An Introduction to Qualitative Research Interviewing, Thousand Oaks: Sage Publications.

Lange, Patricia G. (2007): "Publicly Private and Privately Public: Social Networking on YouTube," Journal of Computer-Mediated Communication, 13:1, 361-380.

Lopez, Lori Kido (2016): Asian American Media Activism: Fighting for Cultural Citizenship, New York: New York University Press.

Maasilta, Mari (2010): Suomen televisioja monikulttuuriset yleisöt, Tampere: Tampere University Press.

Madianou, Mirca (2006): “Contested Communicative Spaces: Rethinking Identities, Boundaries and the Role of the Media among Turkish Speakers in Greece," Journal of Ethnic and Migration Studies, 31:3, 521-541.

Mainsah, Henry (2011): “I Could Well Have Said I Was Norwegian But Nobody Would Believe Me': Ethnic Minority Youths' Self-Representation on Social Network Sites," European Journal of Cultural Studies, 14:2, 179-193.

Mallapragada, Madhavi (2017): "Immigrant Activism: Narratives of the "H-4 Life" by Indian Women on YouTube," Communication, Culture \& Critique, 10:1, 76-92.

Marwick, Alice E. (2013): Status Update: Celebrity, Publicity, and Branding in the Social Media Age, New Haven: Yale University Press.

Mitra, Ananda (2006): "Towards Finding a Cybernetic Safe Place: Illustrations from People of Indian Origin," New Media \& Society, 8:2, 251-268.

Murthy, Dhiraj \& Sanjay Sharma (2019): "Visualizing YouTube's Comment Space: Online Hostility As a Networked Phenomena," New Media \& Society, 21:1, 191-213.

Niemi, Mari K. \& Annu Perälä (2018): “Keiden ääni kuului, keiden 'kriisistä' puhuttiin? Ylen journalistiset valinnat turvapaikanhakijoita käsittelevissä ohjelmissa," Mari K. Niemi \& Topi Houni (eds): Media \& populismi: Työkaluja kriittiseen journalismiin, Tampere: Vastapaino.

Oh, Sanghee \& Sue Yeon Syn (2015): "Motivations for Sharing Information and Social Support in Social Media: A Comparative Analysis of Facebook, Twitter, Delicious, YouTube, and Flickr," Journal of the Association for Information Science and Technology, 66:10, 2045-2060.

Patterson, Ashley (2017): "“I Need Somebody to Hear Me': YouTube and Identity Expression of Biracial Individuals," Multicultural Education Review, 9:2, 105-106.

Pietikäinen, Sari (2002): "Etniset vähemmistöt uutisissa - käsitteitä ja aikaisempien tutkimusten kertomaa", Pentti Raittila (ed.): Etnisyys ja rasismi journalismissa, Tampere: Tampere University Press, 14-29.

Raghavan, Ramya (2009): "Digital Activism on YouTube," available at: https:// googleblog.blogspot.com/2009/07/digital-activism-on-youtube.html (Accessed 24/01/20).

Rastas, Anna (2005): "Racializing Categorization Among Young People in Finland," 


\section{Culture Unbound}

Young, 13:2, 147-166.

Rastas, Anna (2013) "Ethnic Identities and Transnational Subjectivities," Paul Spickard (ed.): Multiple Identities: Migrants, Ethnicity, and Membership, Indiana University Press. 41-60.

Raun, Tobias (2016): Out Online: Trans Self-Representation and Community Building on YouTube, Abingdon: Routledge.

Raun, Tobias (2018): "Capitalizing Intimacy: New Subcultural Forms of Microcelebrity Strategies and Affective Labour on YouTube," Convergence, 24:1, 99-113.

Rekola, Juha (1996): "Excluding the Minorities: Ethnic Representation in the Finnish Press," KEPA Reports No: 10/ 1996, Helsinki: Service Centre for Development Cooperation.

Aksoy, Asu \& Kevin Robins (2000): "Thinking Across Spaces: Transnational Television from Turkey," European Journal of Cultural Studies, 3:3, 343-365.

Römhild, Regina (2017): "Beyond the Bounds of the Ethnic: For Postmigrant Cultural and Social Research," Journal of Aesthetics \& Culture, 9:2, 69-75.

Sallamaa, Daniel (2018): "Ulkoparlamentaarinen äärioikeistoliikehdintä ja maahanmuuttovastaisuus Suomessa," Publications of the Faculty of Social Sciences 97/ 2018, Helsinki: University of Helsinki.

Senft, Theresa M. (2013): "Microcelebrity and the Branded Self," John Hartley, Jean Burgess \& Axel Bruns (eds.): A Companion to New Media Dynamics, Oxford: Blackwell Publishing, 346-354.

Siapera, Eugenia (2010): Cultural Diversity and Global Media: The Mediation of Difference, Chichester: Wiley-Blackwell.

Shohat, Ella \& Robert Stam (1994): Unthinking Eurocentrism: Multiculturalism and the Media, London: Routledge.

Simonsen, Thomas Mosebo (2012): Identity-Formation on YouTube: Investigating Audiovisual Presentations of the Self, doctoral dissertation, Aalborg University.

Statistics Finland (2019): "Number of Persons with Foreign Background Exceeded 400,000," available at: https://www.stat.fi/til/vaerak/2018/02/ vaerak $201802 \quad 2019-06-19$ tie 001 en.html (Accessed 24/01/20).

Stehling, Miriam, Tānja Thomas \& Merle-Marie Kruse (2019): "Media, Participation, and Collaboration in Post-Migrant Societies," Tanja Thomas, Merle-Marie Kruse \& Miriam Stehling (eds.): Media and Participation in Post-Migrant Societies, London: Rowman \& Littlefield International, 3-16.

Strangelove, Michael (2010): Watching YouTube: Extraordinary Videos by Ordinary People, Toronto: University of Toronto Press.

Sugars, Cynthia (2015): "Canadian, Please': The Intimate Space of YouTube Racism," Journal of Canadian Literary and Cultural Studies, 5, 51-71.

SuomiTube.fi (2020): "Kaikki kanavat," available at: https://suomitube.fi/ (Accessed 24/01/20)

Suurpää, Leena (2002): Erilaisuuden hierarkiat: Suomalaisia käsityksiä maahanmuuttajista, suvaitsevaisuudesta ja rasismista, doctoral dissertation, University of Helsinki.

Thumim, Nancy (2012): Self-Representation and Digital Culture, Basingstoke: Palgrave Macmillan.

Van Dijck, Jose (2013): The Culture of Connectivity: A Critical History of Social Media, Oxford: Oxford University Press.

Vergani, Matteo and Dennis Zuev (2011): “Analysis of YouTube Videos Used by Activists in the Uyghur Nationalist Movement: Combining Quantitative and Qualitative Methods," Journal of Contemporary China, 69:20, 205-229.

Wotanis, Lindsey \& Laurie McMillan (2014): "Performing Gender on YouTube: How Jenna Marbles Negotiates a Hostile Online Environment," Feminist Media Studies, 14:6, 912-928.

Yu, Sherry S. \& Matthew D. Matsaganis (2019): "Introduction: Ethnic Media in the Digital Age: New Research from Across the Globe," Sherry S. Yu \& Matthew D. Matsaganis (eds.): Ethnic Media in the Digital Age, Abingdon: Routledge, 1-10. 